\title{
Where Does the Iberian Peninsula Moisture Come From? An Answer Based on a Lagrangian Approach
}

\author{
LUIS GIMENO \\ EPhysLab, Universidade de Vigo, Ourense, Spain \\ RAQUEL NIETO \\ EPhysLab, Universidade de Vigo, Ourense, Spain, and CGUL, IDL, University of Lisbon, \\ Lisbon, Portugal \\ RICARDO M. TRIGO \\ CGUL, IDL, University of Lisbon, and Departamento de Engenharias, \\ Universidade Lusófona, Lisbon, Portugal \\ SERGIO M. Vicente-SERRANO AND JUAN IGNACIO LÓPEZ-MORENO \\ Instituto Pirenaico de Ecología (CSIC), Zaragoza, Spain
}

(Manuscript received 3 June 2009, in final form 4 November 2009)

\begin{abstract}
This study investigated the main sources of moisture in the atmosphere over the Iberian Peninsula (IP) at annual and seasonal scales using FLEXPART, a powerful new 3D Lagrangian diagnosis method that identifies the humidity contributions to the moisture budget of a region. This method can identify moisture sources at lower cost and with greater accuracy than standard isotopic content methods. The results are based on back-tracking analysis of all air masses residing over the IP in the 5-yr period from 2000 to 2004. The results show that the two most important moisture source regions affecting the IP are in a tropical-subtropical North Atlantic corridor that extends from the Gulf of Mexico to the IP, and the IP itself and the surrounding Mediterranean. The importance of these two source areas varies throughout the year, and also with respect to different climatic regions inside the IP. The former source region is the dominant moisture source for the entire IP during winter and in western regions throughout the year, whereas the latter source region dominates the moisture supply to the IP in summer and in the eastern Mediterranean region of the IP throughout the year. The results also demonstrate that winter precipitation in the IP is influenced by both atmospheric instability that forces air masses to rise, and the supply of moisture from the tropical-subtropical North Atlantic corridor on a daily scale and a seasonal basis. Thus, a combination of high (low) moisture supply from the North Atlantic corridor and high (low) atmospheric instability appears to be responsible for the most recent wet (dry) winter in the IP.
\end{abstract}

\section{Introduction}

About $90 \%$ of the water in the atmosphere emanates from the oceans, lakes, and other open water bodies (Quante and Matthias 2006). Through atmospheric transport and associated transfer processes, some of the

Corresponding author address: Luis Gimeno, EPhysLab, Universidade de Vigo, 32004 Ourense, Spain.

E-mail: 1.gimeno@uvigo.es water that evaporates over the oceans reaches the land and may precipitate. It is crucial to understand the processes that govern moisture transport in the troposphere (Trenberth et al. 2003) and how transport might affect the hydrological cycle (Alley et al. 2007).

Understanding of moisture transport processes requires knowledge of how water vapor, which accounts for approximately $0.25 \%$ of the total mass of the atmosphere, is distributed. Water vapor concentration is highly variable both in space and time. The large-scale 
distribution pattern of water vapor largely parallels that of temperature, because equilibrium vapor pressure is dependent on temperature (Clausius-Clapeyron equation). Therefore, the greatest variations in water vapor in space occur with increasing height above the surface; specifically, water vapor concentrations decrease markedly with increasing height. Important variations also occur close to the surface, where concentrations vary by more than three orders of magnitude from $10 \mathrm{ppm}$ by volume (ppmv) in the coldest regions of the earth's atmosphere to as much as $5 \%$ by volume in the warmest regions (Quante and Matthias 2006). Most of the water vapor is concentrated in the tropical atmosphere, which contains more than 3 times as much water as the extratropical atmosphere. The multiyear moisture distributions of areas with the highest and lowest humidity are available from the comprehensive global climatologies of water vapor derived from radiosondes (Peixoto and Oort 1996) or satellites (Dai 2006). However, these moisture distributions can be significantly different from daily humidity distributions, which are more sensitive to prevailing wind fields than to temperature. Analysis at shorter time scales reveals that there are 3-5 major conduits in the atmospheric circulation system in each hemisphere. These conduits are responsible for the transport of large amounts of water in relatively narrow streams from the tropics through the midlatitudes to higher latitudes. They have been referred to as "atmospheric rivers" by Newell et al. (1992) because the amount of water that each transports is comparable to that transported by the Amazon River, which has the greatest flow of all rivers on earth. These streams provide most of the long-distance moisture transport, accounting for $95 \%$ of meridional water vapor flux at $35^{\circ}$ latitude (Zhu and Newell 1998; Ralph et al. 2004).

Moisture advected by wind is not the only source of precipitation in a region (Brubaker et al. 1993); moisture already present in the atmosphere and evaporation from the surface below (recycling component) constitute other possible sources. However, when averaged over long time periods, the contribution of moisture already present in the atmosphere is negligible, so local evaporation (recycling) and transport from remote sources (advection) are the major processes responsible for observed atmospheric moisture at these time scales. In recent decades, hydroclimatologists have developed many methods to quantify the moisture advected in the atmosphere over a particular region, establish how much has been recycled, and derive the ratio between these contributions. The most extensive approaches attempt to determine the net moisture flow through a particular region (Chen et al. 1994; Fernández et al. 2003; Liu and Stewart 2003), and estimate the amount of moisture originating from within the region (the recycling component) and entering it from outside (advection). Other approaches involve tracing water from its source region using forward modeling (Koster et al. 1986; Bosilovich and Schubert 2002), backtrajectory modeling (Dirmeyer and Brubaker 1999), or isotope measurements (Wright et al. 2001).

However, the direct identification of the moisture source regions is considerably more difficult than estimating the ratio between advected and recycled moisture. Isotope analysis has traditionally been used to identify the origin of the moisture that feeds precipitation. This method is based on knowledge of the relationship between the relative proportions of certain isotopes of oxygen and hydrogen, which depend on the conditions (altitude, temperature, distance from the coast) under which the water evaporated to the atmosphere. By establishing an approximate relationship between the isotope content of a sample and its origin, it is possible to identify the moisture sources of a region (Rindsberger et al. 1983; Celle-Jeanton et al. 2001). The main limitations to the widespread use of this method are related to the high economic cost of the sampling campaigns and also to the misleading results that a wide variety of sources from which sampling may take place. An alternative approach is the use of dynamic models of atmospheric transport in a Lagrangian framework that accounts for source and sink regions of moisture. Air parcels are traced during transport in the atmosphere and, to a first-order approximation, change their specific humidity due to precipitation and evaporation processes (Wernli 1997; Wernli et al. 2002). In recent years, a growing number of studies have used Lagrangian approaches to address their various aspects, including moisture transport based on simple analytical models (Dominguez et al. 2006), numerical water vapor tracers (Joussame et al. 1984; Koster et al. 1986), and algorithms that use quasiisentropic back trajectories in combination with modelderived surface fluxes to determine evaporation sources along back trajectories (Dirmeyer and Brubaker 1999; Reale et al. 2001; Dirmeyer and Brubaker 2007).

Most of the earlier-mentioned Lagrangian studies, however, have been limited by methodological (no kinematic trajectories) and conceptual (e.g., assumptions about how surface evaporation is distributed into the overlying air column) shortcomings. Therefore, it is not surprising that more appropriate and sophisticated approaches (although more computationally demanding) have been developed recently, based on the use of fully kinematic trajectories calculated from different Lagrangian particle models. Very similar approaches have been taken by Stohl and James (2004, 2005) and Sodemann et al. $(2008 \mathrm{a}, \mathrm{b})$ to diagnose net water changes along a large number of back trajectories, which enable inferences to be made about the moisture sources in a region. 
Recently, the accuracy and robustness of these approaches have facilitated assessment of the average values for moisture sources in various climatic regions, including the Sahel (Nieto et al. 2006), Iceland (Nieto et al. 2007), the Orinoco River basin (Nieto et al. 2008), and in central Brazil and the La Plata River basin (Drumond et al. 2008).

The main objective of the present study was to apply the Lagrangian diagnosis model used by Stohl and James $(2004,2005)$ to identify the main sources of moisture in the overlying air column over the Iberian Peninsula (IP). To achieve this, we tracked the air masses backward to establish where the air gained or lost moisture. It is important to stress that we identified those regions where the air acquired water vapor as it crossed over them. We considered a standard 5-yr period that lacked extreme phases of the major modes of climate variability at the global climate scale, such as the El Niño-Southern Oscillation (ENSO) or the North Atlantic Oscillation (NAO).

The IP was the target region for this study, as it has interesting features associated with its location at midlatitudes of the Northern Hemisphere, between the Atlantic Ocean and the Mediterranean Sea; these are both important sources of atmospheric moisture, whose influence on the IP could be very different because of the complex topography of the area. The IP orography exerts a strong influence on the way that baroclinic perturbations affect the local climate, as some mountain ranges can shield regions from oceanic moisture advection. Thus, the precipitation regime in the north and west of the IP is strongly affected by the mean annual cycle of the Atlantic storm track and its deviations, whereas in the interior and east of the IP large-scale synoptic systems (Atlantic Ocean influence) and convective precipitation (Mediterranean Sea influence) have similar influences (Trigo et al. 1999, 2000; Castro et al. 2005). Furthermore, the IP has two other important characteristics relevant to analysis of moisture sources: 1) it is on the southern margin of the Atlantic "tropospheric river" (Zhu and Newell 1998), which is the main large-scale feature providing moisture at Atlantic midlatitudes; and 2) the variability of precipitation in some parts of the IP is known to be closely connected to the large-scale North Atlantic atmospheric circulation, including the North Atlantic Oscillation (von Storch et al. 1993; Serrano et al. 1999; Trigo and Palutikof 2001; LópezMoreno et al. 2007). The high frequency of drought periods in the IP (Vicente-Serrano 2006) provides a further reason to subject this region to Lagrangian analysis; the hydrological year 2004/05 was the driest since global precipitation volumes have been recorded (García-Herrera et al. 2007; Santos et al. 2007).

\section{Datasets and analytical procedures}

Our study was based on the method developed by Stohl and James (2004, 2005), which used the Lagrangian particle dispersion model FLEXPART (Stohl et al. 1998) and meteorological analysis data from the European Centre for Medium-Range Weather Forecasts (ECMWF; Uppala et al. 2005) to track atmospheric moisture for the entire atmosphere along trajectories. The atmosphere is divided homogeneously into a large number of "particles," which have a constant mass (further details are provided later) and are distributed homogeneously in the atmosphere according to the distribution of atmospheric mass. In the model, these particles are advected using operational three-dimensional (3D) ECMWF winds. To calculate both the grid-scale advection as well as the turbulent and convective transport of particles, operational ECMWF data were also used as inputs to the model. Their positions and specific humidity values $q$ were temporally interpolated from the ECMWF data, which were recorded every $6 \mathrm{~h}$. The increases $e$ and decreases $p$ in moisture along the trajectory can be calculated from changes in $q$ with time $(e-p=m d q / d t)$, where $m$ is the mass of the particle. When adding $(e-p)$ for all the particles (only those identified as bound for the Iberian Peninsula) in the atmospheric column over an area, it is possible to obtain $(E-P)$, where the surface freshwater flux $(E)$ represents evaporation and $(P)$ is the precipitation rate per unit area. The method can also track $(E-P)$ from any specific region backward in time along the trajectories, choosing those particles that reach the target region at the time of interest, to identify sources of moisture and precipitation. The limitations of the method mainly concern the accuracy of the trajectories and the use of a time derivative of humidity, where unrealistic fluctuations in humidity could be interpreted as moisture fluxes. However, the use of sufficiently long periods minimizes the effects of unrealistic fluctuations. The FLEXPART model computes ECMWF operational analyses every $6 \mathrm{~h}(0000,0600,1200$, and 1800 UTC) at a $1^{\circ} \times 1^{\circ}$ resolution on 60 vertical levels. There are approximately 14 model levels below $1500 \mathrm{~m}$ and 23 below $5000 \mathrm{~m}$. To ensure exact mass balances, vertical winds are calculated using spherical harmonics data as part of the data retrieval procedures at ECMWF. To account for turbulence, the FLEXPART model calculates the trajectory of the particles using analyzed winds plus random motions. In the planetary boundary layer (PBL), these random motions are calculated by solving Langevin equations for Gaussian turbulence (Stohl and Thomson 1999). These equations use Lagrangian time scales and the standard deviations for wind components, which are computed from ECMWF PBL parameters (Hanna 


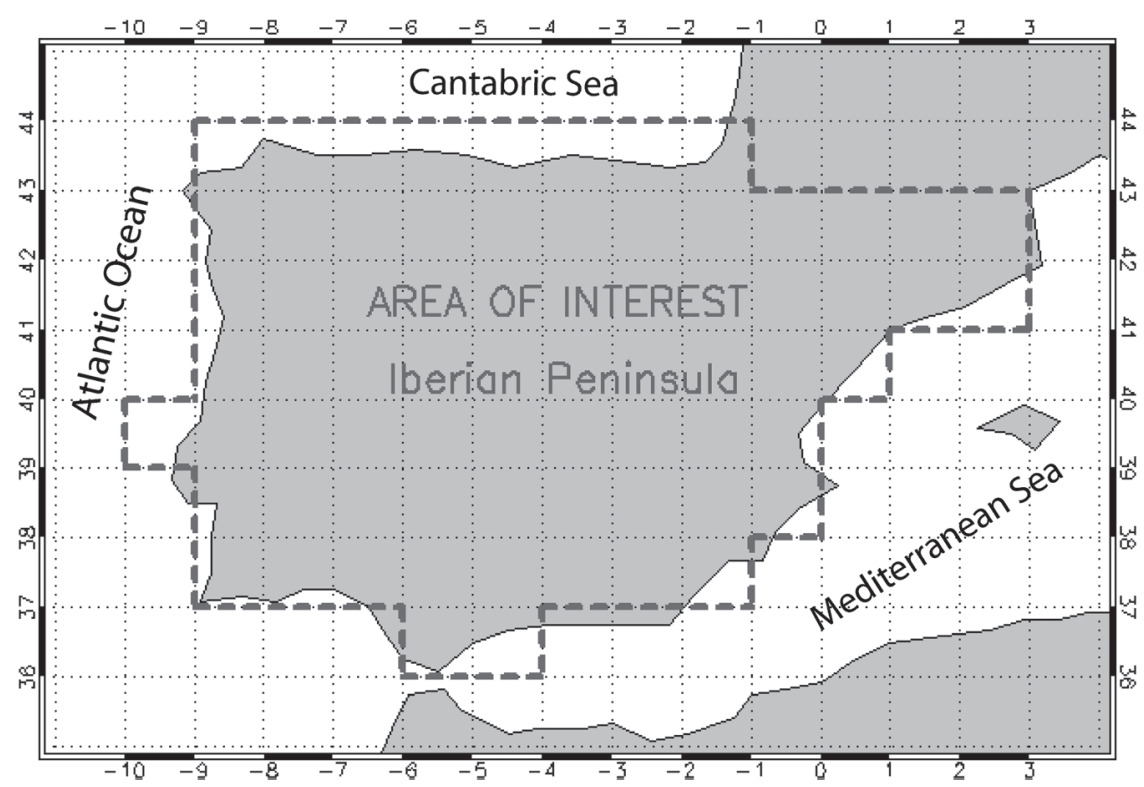

FIG. 1. Map of the study region (IP) showing the area used to compute the backward trajectories (dotted line) on a grid of $1^{\circ}$ lat $\times 1^{\circ}$ lon.

1982). The PBL height is determined using a combination of the Richardson number and the lifting parcel technique (Vogelezang and Holtslag 1996); turbulence outside the PBL is assumed to be very small. Global datasets do not resolve individual convective cells, but they do reproduce the large-scale effects of convection. FLEXPART has various options for the generation of particles and what they represent. In this case, the atmosphere was "filled" homogeneously with particles, each representing a fraction of the total atmospheric mass. Particles were then allowed to move freely (forward in time, but this is arbitrary) with the winds for the duration of the simulation. Full details of the method and its limitations are described by Stohl and James (2004, 2005).

We used the tracks of 1.3 million particles over a $5-\mathrm{yr}$ period (2000-04), computed using ECMWF operational analyses. We traced $(E-P)$ backward from the IP (Fig. 1 shows the study region converted to a grid mesh of $1^{\circ}$ latitude $\times 1^{\circ}$ longitude.) with a transport time limited to 10 days, which is the average residence time of water vapor in the atmosphere (Numaguti 1999). All particles residing over the IP were identified every $6 \mathrm{~h}$ and tracked backward for 10 days. To support this truncated time, we tracked the air mass over the IP backward in time. Figure 2 shows the total number of particles arriving over the IP in the period 2000-04 and the number (percentage) of particles averaged over days 1-10 of transport. This figure shows that about $95 \%$ of the air mass was accounted in this 10-day period. For the first trajectory time step (the first $6 \mathrm{~h}$ backward), practically all the target particles were present in the atmosphere over the IP, and $(E-P)$ represents the region-integrated net freshwater flux. For subsequent trajectory time steps, the particles were dispersed. Consequently, $(E-P)$ represents only the net freshwater flux into the air mass that bounded the atmospheric region of the IP. We calculated $(E-P)$ values for the air particles that traveling to the IP in an atmosphere grid column of $1^{\circ} \times 1^{\circ}$, averaged seasonally, annually, and over the 5-yr period. We designated $(E-P)_{n}$ as the net value for freshwater flux for any prior day $n$; thus, the spatial pattern relative to $(E-P)_{2}$ shows where the moisture over the IP was acquired or lost on the second day of the trajectory. The total $(E-P)$ integrated over days $1-n$ is $(E-P)_{1-n}$; thus, $(E-P)_{1-10}$ is the total for days 1-10. Analysis of $(E-P)$ values clarifies where and when the moisture of those particles reaching the atmosphere over the IP was acquired or lost. It is important to note that we define the "moisture source region" as an area in which an air parcel either absorbed or lost significant amounts of moisture before reaching the atmosphere over the IP, and not just the sources of precipitation.

To validate our results, we used a totally independent procedure to compute the vertically integrated moisture transport (VIMT) and its divergence based on the entire atmospheric mass (not just those air masses that reached the IP) within the window $10^{\circ} \mathrm{S}-70^{\circ} \mathrm{N}, 50^{\circ} \mathrm{E}-100^{\circ} \mathrm{W}$. VIMT is defined as $1 / g \int_{0}^{P_{s}} q \mathbf{v} d p$, where $g$ is the acceleration due to gravity, $q$ is the specific humidity, $P_{s}$ is the surface pressure, and $\mathbf{v}$ is the horizontal wind vector. National Center for Atmospheric Research (NCEP)National Centers for Environmental Prediction (NCAR) 


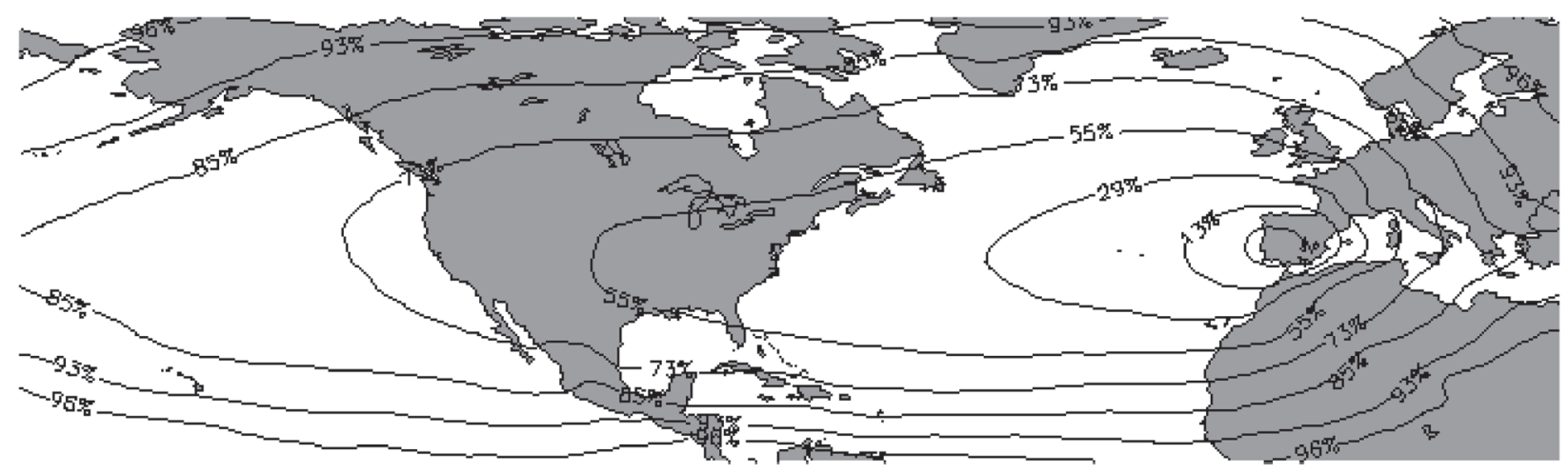

FIG. 2. The particle distribution density averaged annually as a percentage of particles reaching the IP for previous 10 days. The numbers represent the mass at each contour line.

reanalysis data (Kalnay et al. 1996$)$ on a $2.5^{\circ} \times 2.5^{\circ}$ grid were used to compute fluxes and flux divergences for the period 2000-04.

To assess the potential implications of changes in moisture source (location and/or intensity), we evaluated the effect of time-averaged $(E-P)$ values obtained for the major moisture source regions on the corresponding time-averaged precipitation over the IP. We calculated the total precipitation for the IP area defined in our analysis using data from the Global Precipitation Climatology Project (GPCP), version 2, dataset (Huffman et al. 2001). The GPCP is a widely used daily $1^{\circ}$-resolution global grid dataset, based on integrated information from rain gauge observations, satellite retrievals, and sounding observations. The option of using the 40-yr ECMWF Re-Analysis (ERA-40), which also provides precipitation data, was rejected because the overall quality of the data is relatively poor, and the data are only available up to 2002, which did not coincide with our study period (2000-04). On the basis of these constraints, the robust and widely used GPCP precipitation dataset was chosen because it covers the study period at a suitable resolution.

\section{Results and discussion}

\section{a. Sources and sinks of moisture}

\section{1) REgiOnS OF NET UPTAKE OF MOISTURE}

Figure 3 shows the annual $(E-P)_{n}$ fields on the 1st, 3rd, 5th and 10th days of transport and also the 10-day average $(E-P)_{1-10}$. Despite the relative complexity of the back-tracking method, the interpretation of these patterns is straightforward, providing a good representation of source and sink regions of moisture from particles destined for the IP. In those regions characterized by $E-P>0$, evaporation dominated over precipitation, which indicates that air particles destined for the IP in that vertical column gained moisture; such regions were therefore designated as moisture source regions. In contrast, air masses in transit to the IP over regions where precipitation dominated evaporation $(E-P<0)$ had a net loss of moisture; these were designated moisture sink regions. Thus, the $(E-P)_{1}$ map identifies those regions in which the air masses gained $(E-P>0)$ or lost $(E-P<0)$ moisture in the day before they arrived in the IP. This temporal proximity limited the spatial extent of the influence of those zones that were near their destination area. The process of recycling was most relevant during the first day, when air masses were loaded with moisture from the same region into which the moisture fell as precipitation. For the IP, the air masses gain moisture over the surrounding areas of the Mediterranean and Cantabric Seas, and also over the IP territory; the exceptions are the Cantabric and Atlantic coasts, where the air starts to lose moisture. This indicates that the recycling process is of great importance in the central and eastern IP but is of little relevance in the northern and western IP. Spatial patterns relative to $(E-P)_{3}$, $(E-P)_{5}$, and $(E-P)_{10}$ showed that the source and sink regions of moisture for those particles would reach the IP within 3, 5, and 10 days, respectively. Moving backward in time, the spatial extent of those particle source and sink regions expands and is generally less intense; that is, the regions become more diffuse. This finding may reflect two phenomena-increasing dispersion of particles over a wide area, and gaining and losing of moisture for periods longer than five days - through successive processes in their extended trajectory. When average values were calculated for large numbers of particles, random values tended to cancel each other out, except in those zones that contributed to trajectories that were overwhelmingly flowing with a common trajectory component. 

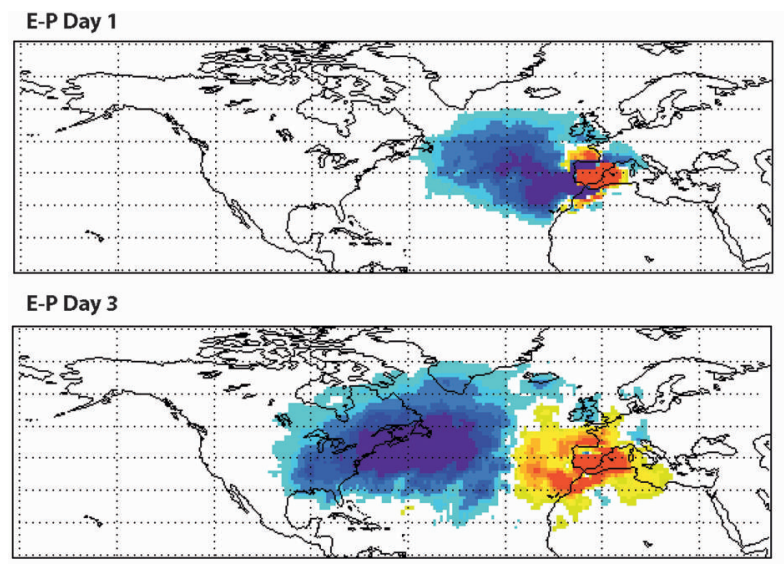

\section{E-P Day 5}

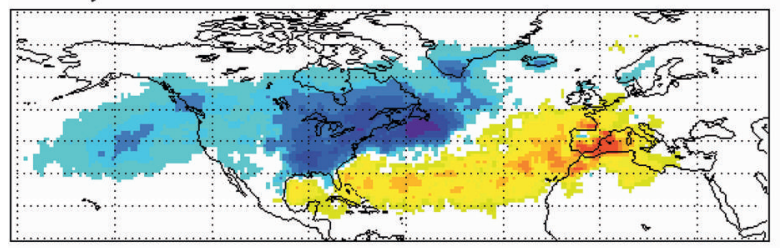

E-P Day 10

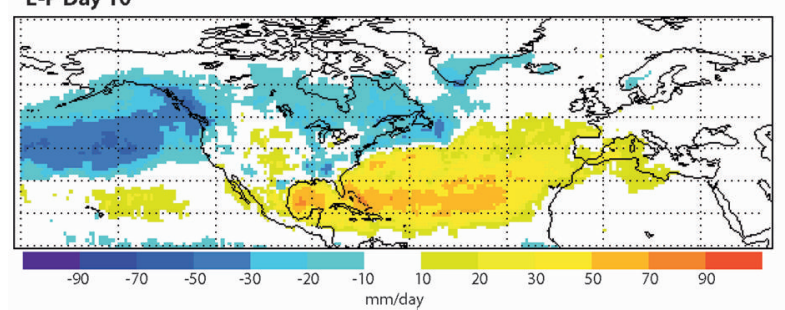

Vertically Integrated Moisture Transport (VIMT)

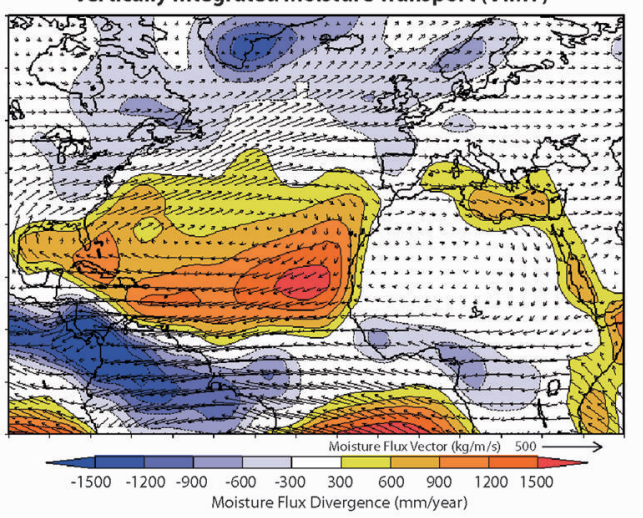

Integrated E-P from day 1 to 10

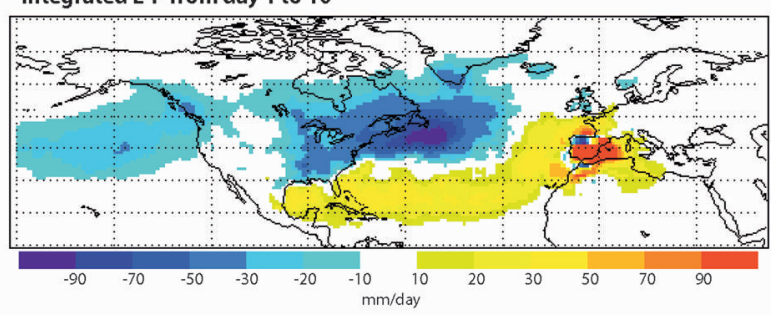

FIG. 3. Annual average values of $(E-P)$ for the period 2000-04 for all the particles bound for the IP region, determined from backward tracking and VIMT and its divergence. (left) Values of $(E-P)$ for days 1, 3, 5, and 10. (right) VIMT and its divergence over (top) $10^{\circ} \mathrm{S}-$ $70^{\circ} \mathrm{N}, 50^{\circ} \mathrm{E}-100^{\circ} \mathrm{W}$ and (bottom) the aggregated values of $E-P$ for the first 10 days $(E-P)_{1-10}$. Units for $(E-P)$ values are mm day ${ }^{-1}$, moisture flux vectors are $\mathrm{kg} \mathrm{m}^{-1} \mathrm{~s}^{-1}$, and moisture divergence contours are $\mathrm{mm} \mathrm{yr}^{-1}$.

Figure 3 suggests that at the annual scale, there are three dominant moisture source regions for the IP. In addition to the recycling process described earlier, the observed patterns of $(E-P)>0$ for $(E-P)_{1}$ and $(E-P)_{3}$ show that the North Atlantic basin close to the IP and the western Mediterranean Sea are the main short-term moisture source regions affecting the IP. These results are consistent with the pattern of the VIMT and its divergence, which are also shown in Fig. 3. It is important to note that the VIMT integral includes all air in the column, whereas the $(E-P)$ calculations include only the particles of air destined for the IP. Over the long term, the vapor flux divergence and $(E-P)$ should be equal. The Atlantic Ocean source reflects the prevailing wind direction in the extratropical region. In contrast, the Mediterranean source includes the well-known poles of maximum positive moisture divergence over the Mediterranean Sea (the southern Ionian Sea and the Gulf of Lions; sources identified by Mariotti et al. 2002), indicating a local net water flux from the Mediterranean Sea to the atmosphere. The spatial pattern for $(E-P)_{5}$ indicates the presence of a source region in the subtropical and tropical North Atlantic Ocean, extending from the Gulf of Mexico to Africa and from $15^{\circ}$ to $30^{\circ} \mathrm{N}$. The relevance of this region is evident with increased backward time analysis; that is, for $(E-P)_{10}$, the source was expanded to a band between $5^{\circ}$ and $40^{\circ} \mathrm{N}$, with the highest values located at subtropical latitudes close to the American continent. This tropical-subtropical source in the southwestern North Atlantic, south of approximately $45^{\circ} \mathrm{N}$, has been reported in studies of other western Europe regions at latitudes higher than the IP (Nieto et al. 2007; Sodemann et al. 2008b). This tropical source is probably associated with tropospheric rivers, which are also related to extratropical cyclones that are responsible for most precipitation on the western side of the extratropical continental latitudes (Ralph et al. 2004, 2005; Bao et al. 2006). The corresponding analysis of sink 
regions highlights those sectors characterized by negative values of $(E-P)$. The patterns for $(E-P)_{1},(E-P)_{3}$, and $(E-P)_{5}$ indicate that the most important characteristic is the considerable loss of moisture over the midlatitude North Atlantic, which is associated with the location of storm tracks that bring substantial precipitation over central and southern Europe. The map of $(E-P)_{1-10}$ corresponds to the integrated behavior of particles from day 1 to day 10 and shows the average of all gains and losses of moisture for the previous 10 days. This aggregated perspective confirms that the two most important moisture source regions are the entire tropicalsubtropical North Atlantic corridor (hereafter TSNA), stretching from the Gulf of Mexico to the IP, and the local source that includes the IP itself and the surrounding western Mediterranean basin (hereafter IPM).

\section{2) AnNuAl CYCLE}

Analysis on an annual basis can be misleading, as it can obscure potentially large variability in the annual cycle. Therefore, we repeated the analysis on a seasonal basis. Figure 4 shows the average values obtained over 10 days for winter [January-March (JFM)], spring [April-June (AMJ)], summer [July-September (JAS)], and fall [October-December (OND)]. The choice of months aimed to maximize the number of seasons involved were between January 2000 and December 2004, taking into account the short period of available data. For comparison, the corresponding seasonal patterns of the VIMT and associated divergence are also included in Fig. 4. In general, the geographic locations of the two main sources $(E-P>0)$ and the sink region $(E-P<0)$ did not vary significantly throughout the year. However, important variations can be seen in the latitudinal extent and the relative magnitude of the sources. In particular, the moisture contribution of the TSNA increased during winter and decreased strongly during summer, when the extent of this region was drastically reduced and its contribution as a source was negligible. In contrast, the contribution of the IPM increased during summer, but it was relatively minor during fall and winter, at which time the IP is mostly characterized by negative values of $(E-P)$. During winter the sink region was displaced to the north, whereas during summer it expanded to encompass almost all of the western and central North Atlantic. These results show the dominance of longdistance transport of moisture relative to recycling during winter, and the importance of recycling during summer. Spring and fall patterns were characterized by intermediate results between those obtained for summer and winter, although fall was overall more similar to winter and spring was more similar to summer. As for the annual analysis, the seasonal results were largely consistent with the corresponding seasonal patterns of the VIMT and associated divergence, also shown in Fig. 4.

\section{b. Water vapor transport}

\section{1) QUANTIFYING THE ROLE OF MAJOR SOURCES}

To evaluate the relative importance of the two sources of moisture to the atmosphere overlying the IP in each season, the water vapor transport was assessed by quantifying the $(E-P)_{n}$ series calculated backward for the target region and integrated over the two sources areas (Fig. 5). As in the $(E-P)$ field computation, the results obtained quantify the sources of water in the atmospheric column over the IP and not only in the land surface of the IP, because they are not conditioned by rainfall events. Here we followed a procedure adopted for quantifying the temporal evolution of the contribution of different moisture sources affecting the Sahel region (Nieto et al. 2006). Figure 5a shows the limits of the source regions and Fig. 5b shows the values obtained for summer and winter $(E-P)_{n}$, for both the TSNA and IPM regions. We quantified the backward computed $(E-P)_{n}$ series for the IP integrated over the TSNA and IPM regions (Fig. 5). Figures 5a and 5b show the values of $(E-P)_{n}$ for these two source regions during summer and winter. These indicate that the IPM was the dominant moisture source for the IP during the 10 days in summer but with a large 1-day maximum and a very significant contribution in the period 1-4 days backward. The TSNA only had a net uptake of summer moisture for the IP from five days backward. The maximum TSNA summer moisture supply occurred 10 days backward and exceeded the IPM supply from 6 days backward, although with a considerably smaller amplitude than occurred in inverse during the first 5 days. The total summer supply from the IPM for days $0-10$ backward was $202 \times 10^{6} \mathrm{~mm} \mathrm{yr}^{-1}$, whereas the corresponding total summer supply from the TSNA for days 5-10 backward was $93 \times 10^{6} \mathrm{~mm} \mathrm{yr}^{-1}$. This indicates that the IPM supplies about twice as much summer moisture to the IP than does the TSNA. A completely different pattern was observed during winter, when the contribution of the IPM was almost negligible relative to the TSNA. The contribution of both sources one day backward was negative, and the contribution of the TSNA was slightly greater than the IPM contribution over two days backward. However, during winter the contribution of the TSNA to moisture supply between 3 and 10 days backward (peak at 6 days) was clearly greater than that from the IPM. The moisture plateau for the TSNA region after six days of back tracking implies that the amount of moisture from this source remains practically constant. The total winter supply from the TSNA region 

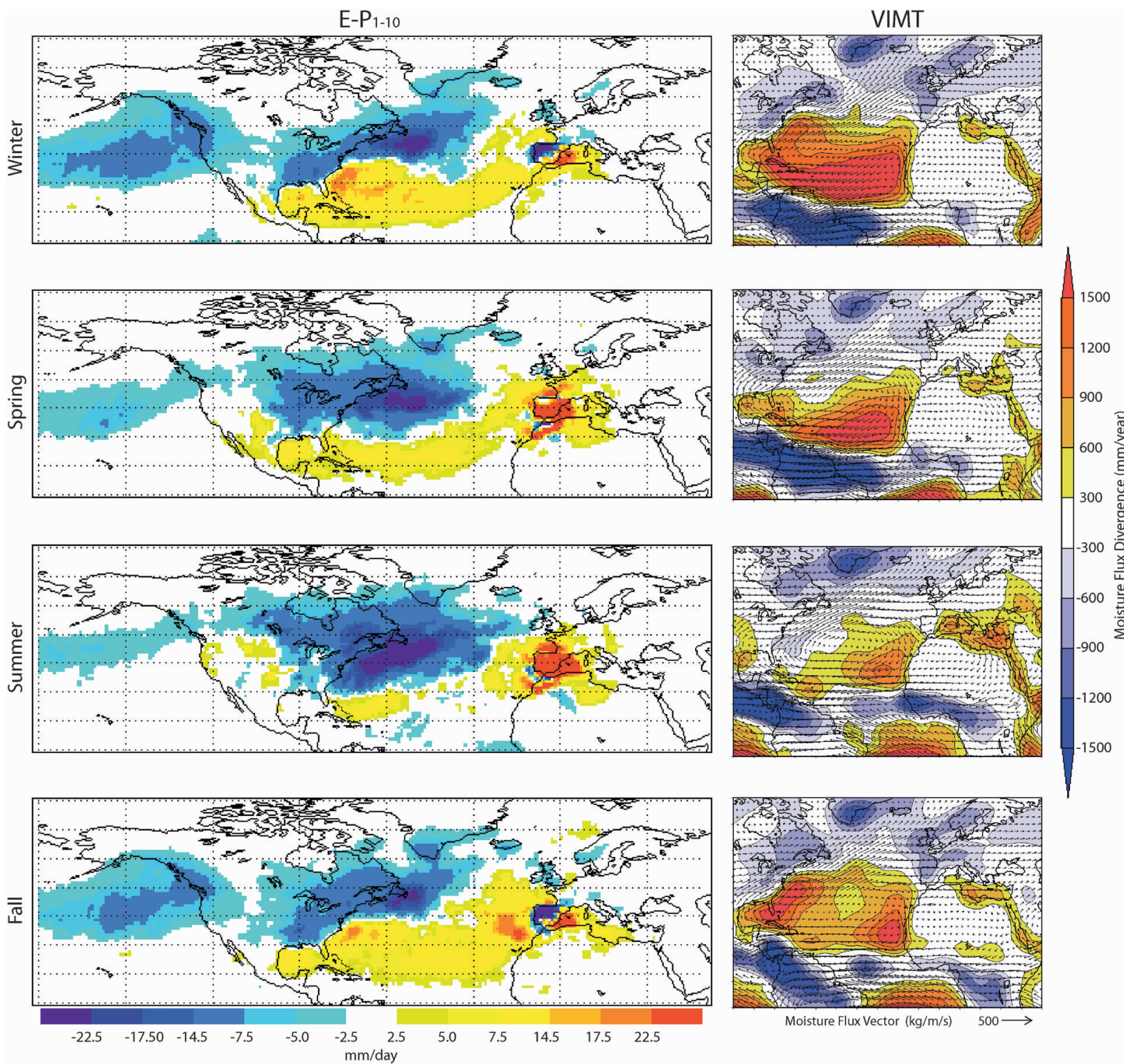

FIG. 4. Same as Fig. 3 but for seasonal average values. (left) Values of $(E-P)$ integrated from 1 to 10 days backward transport $(E-P)_{1-10}$ and (right) VIMT and its divergence over $10^{\circ} \mathrm{S}-70^{\circ} \mathrm{N}, 50^{\circ} \mathrm{E}-100^{\circ} \mathrm{W}$.

from days 2-10 backward was $264 \times 10^{6} \mathrm{~mm} \mathrm{yr}^{-1}$, whereas the corresponding value for the IPM region was $16 \times 10^{6} \mathrm{~mm} \mathrm{yr}^{-1}$, indicating that the former supplies approximately 16 times more winter moisture to the IP than does the IPM.

\section{2) STABLE MOISTURE SOURCES FOR DIFFERENT IBERIAN REGIONS?}

The earlier-mentioned results show that the importance of each source can vary significantly with season. However, it was also predicted that the results would reveal a high degree of spatial variation among different regions inside the IP, as it is known that there is large spatiotemporal variability in the water cycle over the IP. We therefore repeated the $(E-P)$ computation and the analysis on which Fig. 5 was based using four relatively homogeneous climatological areas inside the IP (northwest, north, eastern Mediterranean, and southern-central; Fig. 6). This regionalization was based on studies addressing the various precipitation regimes in the IP over the last two decades (e.g., Rodríguez-Puebla et al. 1998; Serrano et al. 1999; Esteban-Parra et al. 1998, using 
a)

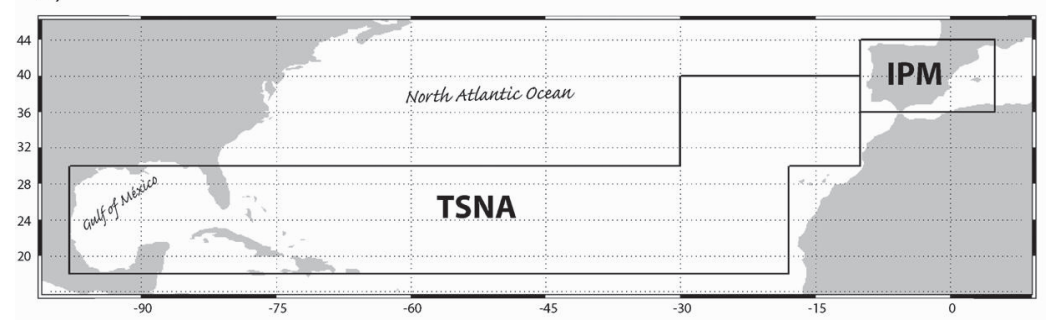

b)

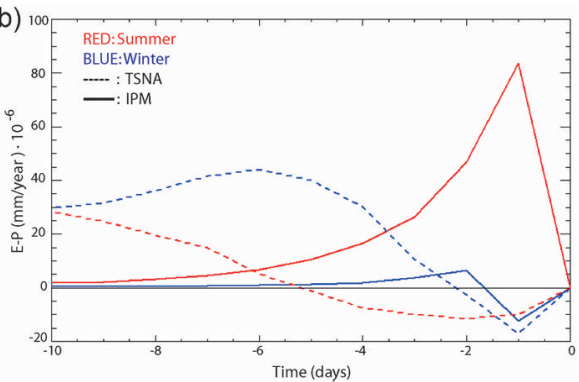

FIG. 5. (a) Main source regions for IP moisture: TSNA and IPM. (b) Seasonal time series of $(E-P)_{n}$ calculated backward for moisture over the IP integrated over the regions indicated in (a): TSNA (dotted line), IPM (continuous line), summer (red lines), and winter (blue lines). These series represent relative values of $(E-P)_{n}$, taking into account the area of each source region (scale multiplied by a factor of $\left.10^{6}\right)$.

principal components analysis; Muñoz-Díaz and Rodrigo 2004, using conglomerate analysis). Figure 6 shows the relative importance of the two sources during winter and summer, and in relation to the four homogeneous climatological areas. These time series were also obtained by quantifying the $(E-P)_{n}$ series computed backward for each area of homogeneous climatological sectors and integrated over the two source regions. The series were divided by the area of the homogeneous climatological areas, which facilitated the comparison. The IPM and TSNA regions maintain their status as the dominant moisture sources for the four homogeneous climatological areas during summer and winter, respectively. However the overall relative importance of the two sources was clearly different, depending on the homogeneous climatological area analyzed. The clearest difference was evident for the northwest (nearest to the Atlantic Ocean) and the eastern Mediterranean (nearest to the Mediterranean Sea) areas in comparing the summer supply of the IPM with the winter supply of the TSNA. For the northwest area, the winter supply of the TSNA from day 2 to day 10 backward was $131.83 \times 10^{-9} \mathrm{~mm} \mathrm{yr}^{-1} \mathrm{~m}^{-2}$, whereas the summer supply of the IPM from day 0 to day 10 backward was $42.10 \times 10^{-9} \mathrm{~mm} \mathrm{yr}^{-1} \mathrm{~m}^{-2}$. Thus, the TSNA region supplied 3.13 times more moisture in winter to the northwest area than did the IPM region in summer. An opposite pattern occurred in the eastern Mediterranean area, where the IPM region supplied $71.17 \times$ $10^{-9} \mathrm{~mm} \mathrm{yr}^{-1} \mathrm{~m}^{-2}$ during summer, whereas the TSNA region supplied only $47.45 \times 10^{-9} \mathrm{~mm} \mathrm{yr}^{-1} \mathrm{~m}^{-2}$ during winter; that is, the IPM supplied approximately 1.5 times more moisture in summer than did the TSNA region in winter. For the north and southern-central areas, the contrast was not as marked, with the TSNA region supplying comparable amounts of moisture in winter $\left(119.36 \times 10^{-9}\right.$ and $105.43 \times 10^{-9} \mathrm{~mm} \mathrm{yr}^{-1} \mathrm{~m}^{-2}$, respectively), whereas the IPM region supplied similar amounts of summer moisture $\left(78.27 \times 10^{-9}\right.$ and $63.17 \times$ $10^{-9} \mathrm{~mm} \mathrm{yr}^{-1} \mathrm{~m}^{-2}$, respectively).

\section{3) MOISTURE TRANSPORT VERSUS INSTABILITY MECHANISMS}

Atmospheric moisture supply is a necessary but not sufficient condition for precipitation, and it is widely accepted that the moisture supply responsible for local moderate-to-heavy precipitation does not come directly from evaporation but mainly though transport (Trenberth et al. 2003). On the basis of our results, it is very likely that moisture from the TSNA makes major contributions to precipitation in the IP in winter, and the IPM makes a major contribution to summer precipitation. However, it does not rain in the absence of a mechanism to force the moist air to rise, that is, if there are no conditions to increase atmospheric instability. The mechanisms that influence precipitation can differ significantly from winter to summer. Precipitation during winter is primarily influenced by moisture supply and instability due to largescale dynamics, but in summer it is mainly influenced by moisture supply and convective instability due to thermodynamic structure and soil factors (Schar et al. 1999; Betts and Viterbo 2005).

As a consequence of the importance of the TSNA to the IP winter moisture supply, especially in the western half of the IP, there is a need to quantify the contribution of this region to winter precipitation. To quantify the contribution of moisture transport from the TSNA in relation to atmospheric instability, we evaluated the region's contribution to winter precipitation in the IP at different atmospheric instability stages. We calculated total precipitation in the IP using data from the GPCP database (Huffman et al. 2001), including only those days when the average precipitation value over the entire IP was $\geq 0.2 \mathrm{~mm}$, a threshold value adopted from Gallego et al. (2006). The application of this criterion gave a total of 259 days during winter for the 2000-04 study period. The TSNA moisture supply was quantified from the averaged $(E-P)_{2-10}$ for the entire IP for each day of precipitation (day 0 corresponds to the rain day). As most 

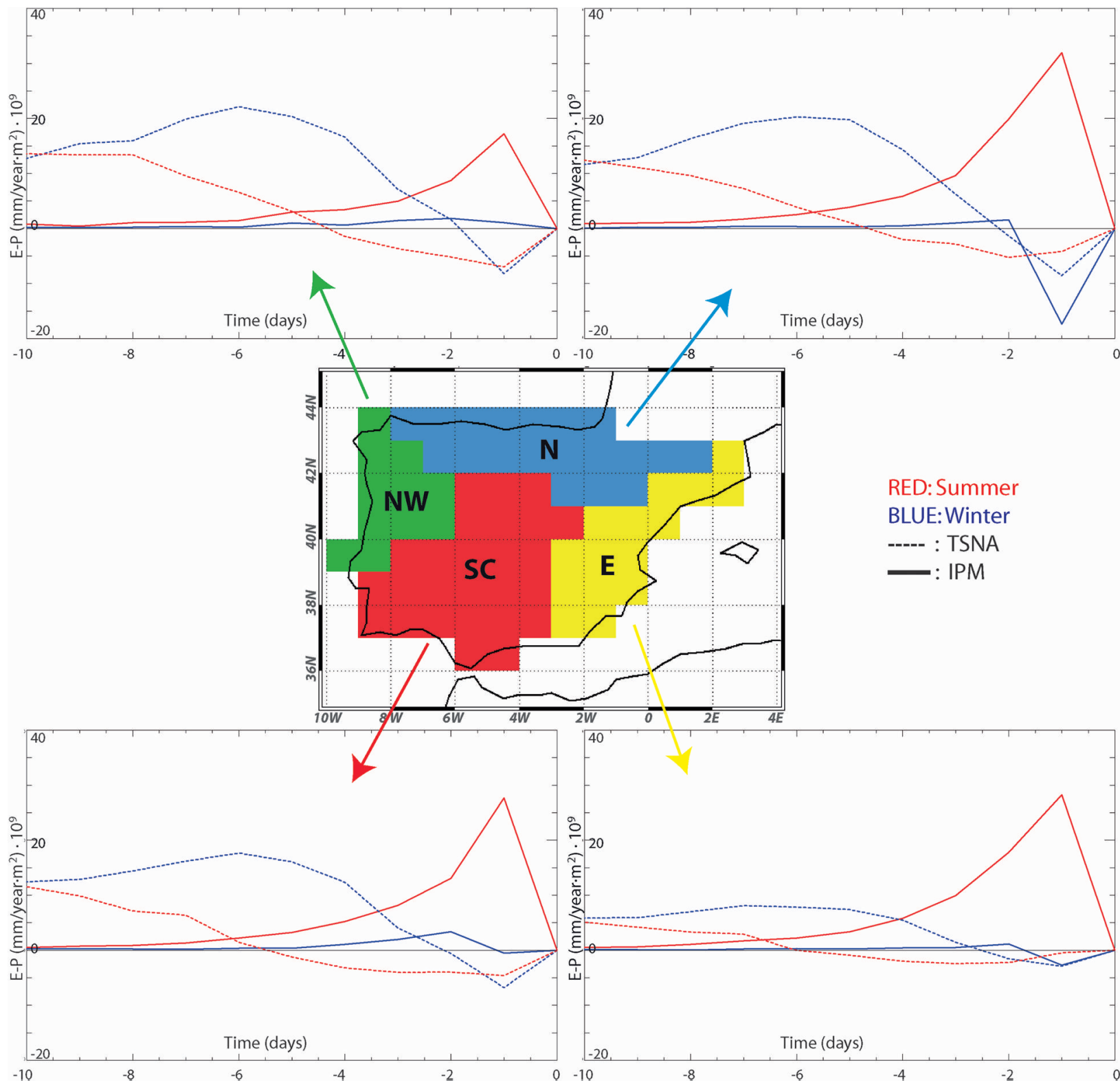

FIG. 6. As in Fig. 5b but for the moisture over the four homogeneous climatological areas inside the IP, indicated in central plot (NW: northwest, N: north, E: eastern Mediterranean, SC: southern-central). The $(E-P)_{n}$ time series are also corrected by each homogeneous climatological areas area (scale multiplied by a factor of $10^{-9}$ ).

winter precipitation in the IP is associated with large-scale synoptic systems, a reasonable parameter for quantifying the instability is the averaged $500-\mathrm{hPa}$ omega field (NCAR-NCEP reanalysis) over a window that includes the IP and surrounding areas $\left(36^{\circ}-44^{\circ} \mathrm{N}, 10^{\circ} \mathrm{W}-5^{\circ} \mathrm{E}\right)$. We used the NECP reanalysis because we lacked permission to use the ECMWF operational analysis. Use of the ERA-40 reanalysis was not possible because it did not cover the full period of the study. The omega values used were obtained after averaging over the selected area $\left(36^{\circ}-44^{\circ} \mathrm{N}, 10^{\circ} \mathrm{W}-5^{\circ} \mathrm{E}\right)$, and no significant differences were expected between the analysis and reanalysis datasets. The dependence of precipitation on the two driving factors (moisture supply and atmospheric instability) was confirmed from the Pearson's correlation coefficients $R=$ -0.43 for precipitation versus omega and $R=0.28$ for precipitation versus $(E-P)_{2-10}$. Both values were statistically significant at the $1 \%$ significance level $(N=259)$, confirming that winter precipitation in the IP is favored by negative values of omega (vertical rising) and high positive values of $(E-P)_{2-10}$ (high moisture supply from the tropics). To assess whether the moisture supply from the 
TSNA is particularly important at a specific level of atmospheric instability, we ranked the precipitation days according to the omega values, then used a moving window of 60 values of omega to correlate $(E-P)_{2-10}$ with precipitation. The results are shown in Fig. 7, where the values of omega represent the medians of the 60 values used for the correlation and the red line shows the $1 \%$ significance level for correlations $(N=60)$. It is notable that the positive correlation between precipitation and the TSNA moisture was significant for low and moderately negative values of omega but not for high values. This could be associated with strong convective precipitation when the importance of local moisture sources is comparatively much greater.

We analyzed the influence of moisture supply on precipitation during summer versus convective instability, measured as the surface-based lifted index (SBLI). The SBLI is calculated by taking a representative surface air parcel and lifting it adiabatically to $500 \mathrm{hPa}$. The algebraic difference between this air parcel and the sounding temperature at $500 \mathrm{hPa}$ denotes the SBLI. Higher negative values of the SBLI indicate greater energy availability for parcel ascent. To complete the study, we assessed the importance of the omega value, soil moisture, surface relative humidity, and total precipitation water during summer. The application of the precipitation threshold noted earlier reduced the total number of rain days to 251 during summer. The variables cited were calculated by averaging the NCAR-NCEP data for the same windows that were used for the omega analysis. The correlation coefficients were computed to assess the possible dependence of precipitation on these factors. Statistically significant ( $1 \%$ significance level) results were found for omega $(R=-0.21)$, soil moisture $(R=0.22)$, and surface relative humidity $(R=0.20)$; SBLI $(R=-0.13)$ was only significant at the $5 \%$ level. From these values, the importance of dynamic instability on precipitation during summer is also evident, through the poor correlation of summer precipitation with SBLI and the lack of any significant correlation of summer precipitation with the supply of moisture from the IPM. This result is logical considering the mesoscale character of most of the summer precipitation in the IP and the average values of precipitation and the different indices used in this study for the IP.

\section{4) THE ROLE OF WET AND DRY YEARS}

The contribution to IP precipitation (including location and intensity) of the TSNA moisture source under dry or wet winter conditions in the IP was also assessed. Precipitation over the IP during the relatively short study period was characterized by two extreme winters. Between November 2004 and March 2005, there was

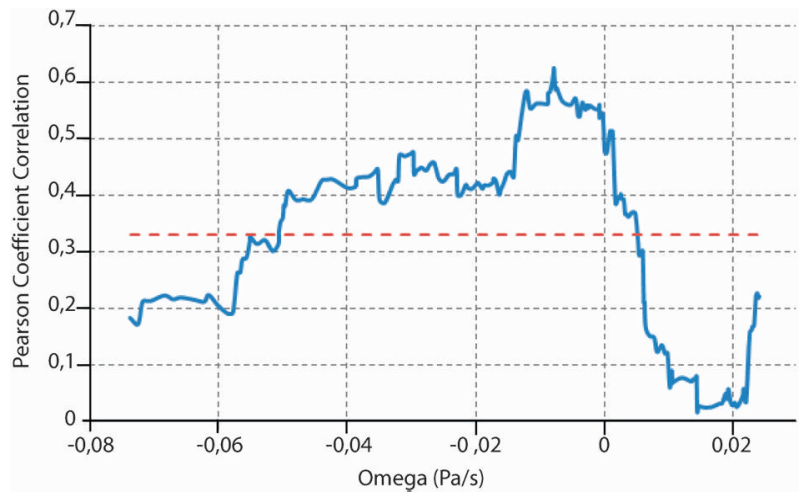

FIG. 7. Winter correlation (blue line) between precipitation $(\geq 0.2 \mathrm{~mm}$ ) over entire IP and TSNA moisture supply, quantified by the averaged $(E-P)_{2-10}$ for ordered intervals of $500-\mathrm{hPa}$ omega values over the IP. Correlations were made using a moving window of 60 values of omega. The abscissa represents the median of each omega interval. The red dotted line shows the $1 \%$ significance level for correlations $(N=60, R=0.33)$.

a major drought in the IP (García-Herrera et al. 2007; Santos et al. 2007), with the Spanish Meteorological Institute recording Spain's driest winter since records began in 1943, and Portugal also recorded its worst drought in 25 yr. The U.S. Department of Agriculture's Foreign Agricultural Service estimated rainfall totals for Spain and Portugal to be as much as $75 \%$ below average between September 2004 and February 2005 (available online at http://earthobservatory.nasa.gov/NaturalHazards/view. php?id=14719). In contrast, there was very intense precipitation over the IP between November 2000 and March 2001, particularly in the western half, which is most affected by the transport of moisture from the TSNA region. These extremely different winter conditions enabled comparison of the different moisture supplies and extension of the TSNA for these distinct periods, providing a better understanding of the role of the TSNA in the winter precipitation in the IP. The very different conditions that characterized these two winter periods is evident in terms of precipitation anomalies (GPCP) and the anomaly fields relative to the omega and $850-\mathrm{hPa}$ zonal winds (NCAR-NCEP reanalysis; Fig. 8). The anomalies were calculated using the period 1968-96 as a reference. The areas of greatest (least) precipitation in wet (dry) winters were mainly located in the western IP and were associated with very strong negative (positive) anomalies of omega and strong westerly (easterly) zonal wind anomalies. Thus, both of the precipitation forcing mechanisms described earlier (atmospheric instability and moisture supply from the Atlantic Ocean) appear to be positively coupled to produce extreme periods. In fact, both periods were associated with absolute maxima (negative/positive) anomalies of 500 -hPa omega for the western IP $\left(37.5^{\circ}-45^{\circ} \mathrm{N}, 5^{\circ}-10^{\circ} \mathrm{W}\right)$ 


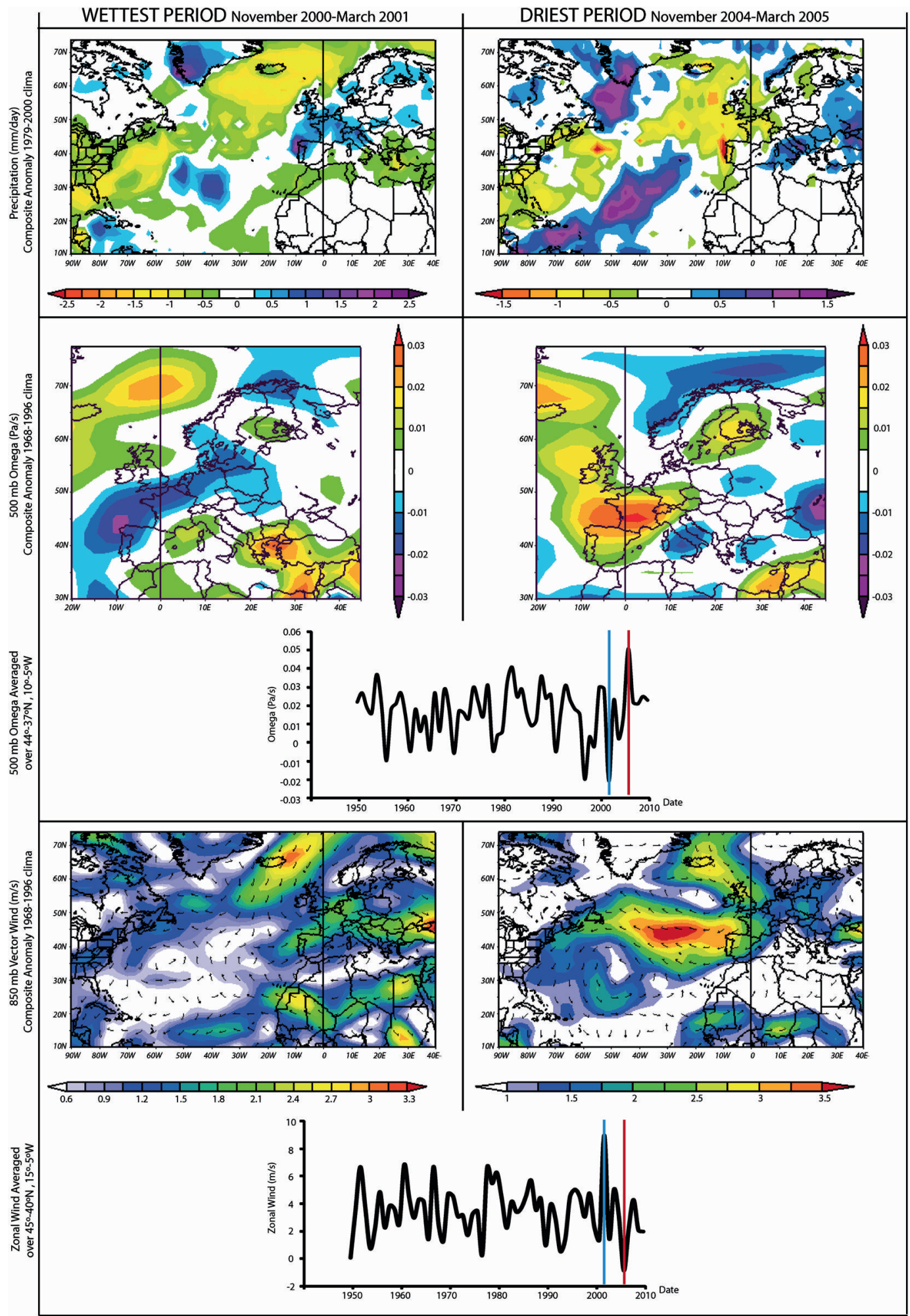

FIG. 8. Comparison of the (left) wettest (Nov 2000-Mar 2001) and (right) driest (Nov 2004-Mar 2005) winters in the IP in terms of (top) precipitation, (middle) 500-hPa omega, and (bottom) 850-hPa zonal wind anomalies. Time series of anomalies are computed using 1968-96 as reference period; blue (red) line denotes wettest (driest) winter. Time series of omega and zonal winds averaged for the box $45^{\circ}-37.5^{\circ} \mathrm{N}, 10^{\circ}-5^{\circ} \mathrm{W}$. 


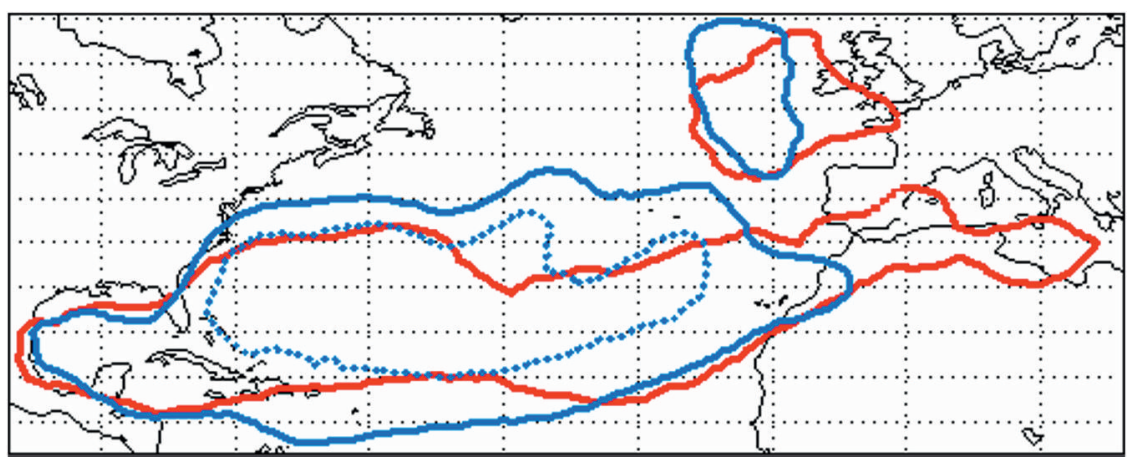

FIG. 9. The $(E-P)_{1-10}$ contours of 1 (solid lines) and $3 \mathrm{~mm} \mathrm{day}^{-1}$ (dotted line) during the wettest (2000/01; blue lines) and driest (2004/05; red lines) winter for the IP region, excluding the eastern Mediterranean area $(E)$.

during the entire NCAR-NCEP reanalysis period (1948-2008; see the temporal series in Fig. 8). In evaluating the different extension and contribution of the TSNA moisture supply to the western IP during these two periods, we excluded the eastern Mediterranean area because of its very different precipitation regime and the relatively minor importance of the TSNA. Figure 9 shows the 1 (solid lines) and $3 \mathrm{~mm}$ day $^{-1}$ (dotted lines) contours for $(E-P)_{1-10}$ during both winters. The blue lines correspond to the wet period and the single red line (no values greater than $3 \mathrm{~mm}$ day $^{-1}$ ) corresponds to the dry period. It is notable that over the Atlantic basin, the latitudinal extension of the TSNA was slightly larger for the wet winter than for the dry winter. Moreover, the intensity of this source was much greater for the wet winter, with the area in this period characterized by values greater than $3 \mathrm{~mm}$ day $^{-1}$ stretching between the Caribbean and the southern Azores. In contrast, during the dry year, similarly high values were completely absent from the entire Atlantic region. These results provide additional evidence that the combined effect of high/low moisture supply from the TSNA region and high/low atmospheric instability are responsible for extreme winter precipitation in the IP. Interestingly, during the dry year, the western Mediterranean and northern Africa appeared to supply some moisture to the IP, but this did not occur during the wet winter.

\section{Summary and conclusions}

We used a robust and recently developed dynamic 3D back-tracking algorithm to assess the location and relative importance of moisture sources for the atmosphere overlying the IP. The IP was chosen because of its location between two important sources of atmospheric moisture-the Atlantic Ocean and the Mediterranean Sea-and because of the large spatial and temporal variability in precipitation that occurs in this area (Serrano et al. 1999; Trigo et al. 2004).

We studied the average conditions over a 5-yr period (2000-04) using available data. Despite the short temporal time frame, this can be considered a standard period at the global climate scale because no extremes occurred in the major modes of climate variability, such as El Niño-Southern Oscillation (ENSO) or North Atlantic Oscillation (NAO). The main findings can be summarized as follows:

- We established that the most important moisture source regions affecting the IP are 1) the tropical-subtropical North Atlantic corridor stretching between the Gulf of Mexico and the Iberian Peninsula (TSNA) and 2) the "local" source including the IP and the surrounding Mediterranean area (IPM). In this regard, a significant finding was the identification of the importance of the TSNA and its longitudinal extension to the Caribbean; moisture fluxes for this region and its divergence have not been apparent in the patterns derived from classical analyses, and this represents a major advantage of the Lagrangian approach.

- The importance of the two source regions varies throughout the year. The IPM is the dominant summer moisture source for the IP, supplying twice as much moisture as the TSNA. This contribution remained positive over the 10-day analysis period but was greater between 1 and 4 days backward, with a clear prominent maximum 1 day prior to arrival over the IP. On the other hand, the TSNA dominated as a moisture source during the winter months, when the contribution of the IPM was almost negligible. The moisture supply from the TSNA was from day 2 to day 10 and was about 16 times larger than the IPM supply.

- Accumulated empirical data for both Portugal and Spain were used to further discriminate the results, particularly in assessment of the importance of the two 
major moisture sources for different homogeneous climatic regions of the IP. Thus, we applied the same method to assess the relative importance of the TSNA and IPM for four homogeneous regions widely used in regional IP studies. The winter supply of moisture from the TSNA region dominated the hydrological cycle in the western part of the IP, which was thus more influenced by the Atlantic Ocean. In contrast, the IPM dominated the summer moisture supply in the hydrological cycle of the eastern Mediterranean part of the IP.

- The results also suggest that winter precipitation on the IP is influenced by both atmospheric instability, which forces air masses to rise, and the supply of moisture from the TSNA. This interpretation is valid at the daily scale and on a seasonal basis. Thus, the larger the supply of moisture originating in the TSNA during the 10 days prior to a rainy day in the IP, the greater the precipitation during that day. In addition, a combination of high (low) moisture supply from the TSNA and high (low) atmospheric instability is responsible for humid (dry) winters in the IP.

- Lastly, we evaluated the contribution of the TSNA moisture source to the IP on a wet and on a dry year. It was found that over the Atlantic basin, the latitudinal extension of the TSNA source was considerably larger during the wet winter (2000/01) than during the dry winter (2004/05). It was also found that the intensity of the source was considerably higher during the wet winter, with the area characterized by higher values from the Caribbean and southern Azores, whereas during the dry winter, similarly high values were completely absent for the entire Atlantic region. Because these results were based on analysis of only one wet and one dry year, it is clear that a longer temporal database is required to evaluate their significance.

Recent changes in atmospheric circulation patterns are partially responsible for the trend of declining precipitation over the IP (Paredes et al. 2006) and the occurrence of major drought episodes (García-Herrera et al. 2007; Santos et al. 2007). Furthermore, a tendency toward a drier climate with a higher frequency of drought events is consistent with current climate change scenarios (e.g., Giorgi 2006). In fact, climate model simulations of the Mediterranean basin, including the IP, show a very consistent signal toward a dry future and a general increase in the frequency and duration of drought episodes (Alley et al. 2007). However, on the basis of the results of the present study, global climate models (GCMs) should be able to adequately reproduce the large-scale mechanisms that control precipitation over the IP (e.g., NAO) and include the freshwater flux balance over the western Mediterranean, particularly between the Caribbean and Iberia.

Acknowledgments. This work was supported by the Spanish Ministry of Education (MEC) under Grants CGL2008-05968-C02-02 (MSM) and CGL2004-05187C03-02/CLI (DINPRE). L. Gimeno and R. Trigo received support from the EU's Sixth Framework Programme (CIRCE). L. Gimeno, R. Nieto, and R. Trigo also received some support from the Portuguese-Spanish integrated action funded by CRUP (Grant E-16/2008) and MCYT (Grant HP2007-0064).

\section{REFERENCES}

Alley, R. B., and Coauthors, 2007: Summary for policymakers. Climate Change 2007: The Physical Science Basis, S. Solomon et al. Eds., Cambridge University Press, 18 pp. [Available online at http:// www.ipcc.ch/pdf/assessment-report/ar4/wg1/ar4-wg1-spm.pdf.]

Bao, J.-W., S. A. Michelson, P. J. Neiman, F. M. Ralph, and J. M. Wilczak, 2006: Interpretation of enhanced integrated water vapor bands associated with extratropical cyclones: Their formation and connection to tropical moisture. Mon. Wea. Rev., 134, 1063-1080.

Betts, A. K., and P. Viterbo, 2005: Land-surface, boundary layer, and cloud-field coupling over the southwestern Amazon in ERA-40. J. Geophys. Res., 110, D14108, doi:10.1029/2004JD005702.

Bosilovich, M. G., and S. D. Schubert, 2002: Water vapor tracers as diagnostics of the regional hydrologic cycle. J. Hydrometeor. 3, 149-165.

Brubaker, K. L., D. Entekhabi, and P. Eagleson, 1993: Estimation of continental precipitation recycling. J. Climate, 6, 1077-1089.

Castro, M., J. Martín-Vide, and S. Alonso, 2005: The climate of Spain: Past, present and scenarios for the 21st century. A preliminary assessment of the impacts in Spain due to the effects of climate change, J. M. Moreno, Ed., Ministry of the Environment ECCE Project Final Rep., 1-62.

Celle-Jeanton, H., Y. Travi, and B. Blavoux, 2001: Isotopic Typology of the Precipitation in the Western Mediterranean Region at Three Different Time Scales. Geophys. Res. Lett., 28, 1215-1218.

Chen, T.-C., J. Pfaendtner, and S.-P. Weng, 1994: Aspects of the hydrological cycle of the ocean-atmosphere system. J. Phys. Oceanogr., 24, 1827-1833.

Dai, A., 2006: Recent climatology, variability, and trends in global surface humidity. J. Climate, 19, 3589-3606.

Dirmeyer, P. A., and K. L. Brubaker, 1999: Contrasting evaporative moisture sources during the drought of 1988 and the flood of 1993. J. Geophys. Res., 104 (D16), 19 383-19 397.

— , and —, 2007: Characterization of the global hydrologic cycle from a back-trajectory analysis of atmospheric water vapor. J. Hydrometeor., 8, 20-37.

Dominguez, F., P. Kumar, X.-Z. Liang, and M. Ting, 2006: Impact of atmospheric moisture storage on precipitation recycling. J. Climate, 19, 1513-1530.

Drumond, A., R. Nieto, L. Gimeno, and T. Ambrizzi, 2008: A Lagrangian identification of major sources of moisture over Central Brazil and La Plata Basin. J. Geophys. Res., 113, D14128, doi:10.1029/2007JD009547.

Esteban-Parra, M. J., F. S. Rodrigo, and Y. Castro-Díez, 1998: Spatial and temporal patterns of precipitation in Spain for the period 1880-1992. Int. J. Climatol., 18, 1557-1574. 
Fernández, J., J. Sáenz, and E. Zorita, 2003: Analysis of wintertime atmospheric moisture transport and its variability over southern Europe in the NCEP Reanalyses. Climate Res., 23, 195-215.

Gallego, M. C., J. A. García, J. M. Vaquero, and V. L. Mateos, 2006: Changes in frequency and intensity of daily precipitation over the Iberian Peninsula. J. Geophys. Res., 111, D24105, doi:10.1029/2006JD007280

García-Herrera, R., D. Paredes, R. M. Trigo, I. F. Trigo, E. Hernández, D. Barriopedro, and M. A. Mendes, 2007: The outstanding 2004/05 drought in the Iberian Peninsula: Associated atmospheric circulation. J. Hydrometeor., 8, 483-498.

Giorgi, F., 2006: Climate change hot-spots. Geophys. Res. Lett., 33, L08707, doi:10.1029/2006GL025734.

Hanna, S. R., 1982: Applications in air pollution modeling. Atmospheric Turbulence and Air Pollution Modelling: A Course Held in The Hague, F. T. M Nieuwstadt and H. van Dop, Eds., D. Reidel, 275-310.

Huffman, G. J., R. F. Adler, M. M. Morrissey, S. Curtis, R. Joyce, B. McGavock, and J. Susskind, 2001: Global precipitation at one-degree daily resolution from multisatellite observations. J. Hydrometeor., 2, 36-50.

Joussame, S., J. Jouzel, and R. Sadourny, 1984: A general circulation model of water isotope cycles in the atmosphere. Nature, 311, 24-29.

Kalnay, E., and Coauthors, 1996: The NCEP/NCAR 40-Year Reanalysis Project. Bull. Amer. Meteor. Soc., 77, 437-471.

Koster, R., J. Jouzel, R. Suozzo, G. Russell, W. Broecker, D. Rind, and P. Eagleson, 1986: Global sources of local precipitation as determined by the NASA/GISS GCM. Geophys. Res. Lett., 13, 121-124.

Liu, J., and R. E. Stewart, 2003: Water vapor fluxes over the Saskatchewan River basin. J. Hydrometeor., 4, 944-959.

López-Moreno, J. I., S. Beguería, S. M. Vicente-Serrano, and J. M. García-Ruiz, 2007: Influence of the North Atlantic Oscillation on water resources in central Iberia: Precipitation, streamflow anomalies, and reservoir management strategies. Water Resour. Res., 43, W09411, doi:10.1029/2007WR005864.

Mariotti, A., M. V. Struglia, N. Zeng, and K. M. Lau, 2002: The hydrological cycle in the Mediterranean region and implications for the water budget of the Mediterranean Sea. J. Climate, 15, 1674-1690.

Muñoz-Díaz, D., and F. S. Rodrigo, 2004: Spatio-temporal patterns of seasonal rainfall in Spain (1912-2000) using cluster and principal component analysis: Comparison. Ann. Geophys., 22, 1435-1448.

Newell, R. E., N. E. Newell, Y. Zhu, and C. Scott, 1992: Tropospheric rivers? A pilot study. Geophys. Res. Lett., 19, 2401-2404.

Nieto, R., L. Gimeno, and R. M. Trigo, 2006: A Lagrangian identification of major sources of Sahel moisture. Geophys. Res. Lett., 33, L18707, doi:10.1029/2006GL027232.

,,-- D. Gallego, and R. Trigo, 2007: Contributions to the moisture budget of airmasses over Iceland. Meteor. Z., 16, 37-44.

—, D. Gallego, R. Trigo, P. Ribera, and L. Gimeno, 2008: Dynamic identification of moisture sources in the Orinoco basin in equatorial South America. Hydrol. Sci. J., 53, 602-617.

Numaguti, A., 1999: Origin and recycling processes of precipitating water over the Eurasian continent: Experiments using an atmospheric general circulation model. J. Geophys. Res., 104, 1957-1972.

Paredes, D., R. M. Trigo, R. García-Herrera, and I. F. Trigo, 2006: Understanding precipitation changes in Iberia in early spring: Weather typing and storm-tracking approaches. J. Hydrometeor., 7, 101-113.
Peixoto, J. P., and A. H. Oort, 1996: The climatology of relative humidity in the atmosphere. J. Climate, 9, 3443-3463.

Quante, M., and V. Matthias, 2006: Water in the Earth's atmosphere. J. Phys. IV, 139, 37-61.

Ralph, F. M., P. J. Neiman, and G. A. Wick, 2004: Satellite and CALJET aircraft observations of atmospheric rivers over the eastern North Pacific Ocean during the winter of 1997/98. Mon. Wea. Rev., 132, 1721-1745.

_ _ — , and R. Rotunno, 2005: Dropsonde observations in low-level jets over the northeastern Pacific Ocean from CALJET-1998 and PACJET-2001: Mean vertical-profile and atmospheric-river characteristics. Mon. Wea. Rev., 133, 889-891.

Reale, O., L. Feudale, and B. Turato, 2001: Evaporative Moisture Sources During a Sequence of Floods in the Mediterranean Region. Geophys. Res. Lett., 28, 2085-2088.

Rindsberger, M., M. Magaritz, I. Carmi, and D. Gilad, 1983: The relation between air mass trajectories and the water isotope composition of rain in the Mediterranean Sea area. Geophys. Res. Lett., 10, 43-46.

Rodríguez-Puebla, C., A. H. Encinas, S. Nieto, and J. Garmendia, 1998: Spatial and temporal patterns of annual precipitation variability over the Iberian Peninsula. Int. J. Climatol., 18, 299-316.

Santos, J., J. Corte-Real, and S. Leite, 2007: Atmospheric largescale dynamics during the 2004/2005 winter drought in Portugal. Int. J. Climatol., 27, 571-586.

Schär, C., D. Lüthi, U. Beyerle, and E. Heise, 1999: The soilprecipitation feedback: A process study with a regional climate model. J. Climate, 12, 722-741.

Serrano, A., J. A. García, V. L. Mateos, M. L. Cancillo, and J. Garrido, 1999: Monthly modes of variation of precipitation over the Iberian Peninsula. J. Climate, 12, 2894-2919.

Sodemann, H., V. Masson-Delmotte, C. Schwierz, B. M. Vinther, and $\mathrm{H}$. Wernli, 2008a: Interannual variability of Greenland winter precipitation sources: 2. Effects of North Atlantic Oscillation variability on stable isotopes in precipitation. J. Geophys. Res., 113, D12111, doi:10.1029/2007JD009416.

_ C. Schwierz, and H. Wernli, 2008b: Interannual variability of Greenland winter precipitation sources: Lagrangian moisture diagnostic and North Atlantic Oscillation influence. J. Geophys. Res., 113, D03107, doi:10.1029/2007JD008503.

Stohl, A., and D. J. Thomson, 1999: A density correction for Lagrangian particle dispersion models. Bound.-Layer Meteor., 90, 155-167.

— branch of the global water cycle. Part I: Method description, validation, and demonstration for the August 2002 flooding in central Europe. J. Hydrometeor., 5, 656-678.

, and - 2005: A Lagrangian analysis of the atmospheric branch of the global water cycle. Part II: Moisture transports between earth's ocean basins and river catchments. J. Hydrometeor., 6, 961-984.

- M. Hittenberger, and G. Wotawa, 1998: Validation of the Lagrangian particle dispersion model FLEXPART against large scale tracer experiment data. Atmos. Environ., 32, 4245-4264.

Trenberth, K. E., A. Dai, R. M. Rasmussen, and D. B. Parsons, 2003: The changing character of precipitation. Bull. Amer. Meteor. Soc., 84, 1205-1217.

Trigo, I. F., T. D. Davies, and G. R. Bigg, 1999: Objective climatology of cyclones in the Mediterranean region. J. Climate, 12, 1685-1696.

- - , and $\longrightarrow$, 2000: Decline in Mediterranean rainfall caused by weakening of Mediterranean cyclones. Geophys. Res. Lett., 27, 2913-2916. 
Trigo, R. M., and J. P. Palutikof, 2001: Precipitation scenarios over Iberia: A comparison between direct GCM output and different downscaling techniques. J. Climate, 14, 4422-4446.

—_, D. Pozo-Vazquez, T. J. Osborn, Y. Castro-Díez, S. GámisFortis, and M. J. Esteban-Parra, 2004: North Atlantic Oscillation influence on precipitation, river flow and water resources in the Iberian Peninsula. Int. J. Climatol., 24, 925-944.

Uppala, S. M., and Coauthors, 2005: The ERA-40 Re-Analysis. Quart. J. Roy. Meteor. Soc., 131, 2961-3012.

Vicente-Serrano, S. M., 2006: Spatial and temporal analysis of droughts in the Iberian Peninsula (1910-2000). Hydrol. Sci. J., 51, 83-97.

Vogelezang, D. H. P., and A. A. M. Holtslag, 1996: Evaluation and model impacts of alternative boundary-layer height formulations. Bound.-Layer Meteor., 81, 245-269. von Storch, H., E. Zorita, and U. Cubasch, 1993: Downscaling of global climate change estimates to regional scales: An application to Iberian rainfall in wintertime. J. Climate, 6, 1161-1171.

Wernli, H., 1997: A Lagrangian-based analysis of extratropical cyclones. II: A detailed case-study. Quart. J. Roy. Meteor. Soc., 123, 1677-1706.

_ S. Dirren, M. Liniger, and M. Zillig, 2002: Dynamical aspects of the life cycle of the winter storm "Lothar" (24-26 December 1999) Quart. J. Roy. Meteor. Soc., 128, 405-429.

Wright, W. E., A. Long, A. C. Comrie, S. W. Leavitt, T. Cavazos, and C. Eastoe, 2001: Monsoonal moisture sources revealed using temperature, precipitation and precipitation stable isotope timeseries. Geophys. Res. Lett., 28, 787-790.

Zhu, Y., and R. E. Newell, 1998: A proposed algorithm for moisture fluxes from atmospheric rivers. Mon. Wea. Rev., 126, 725-735. 